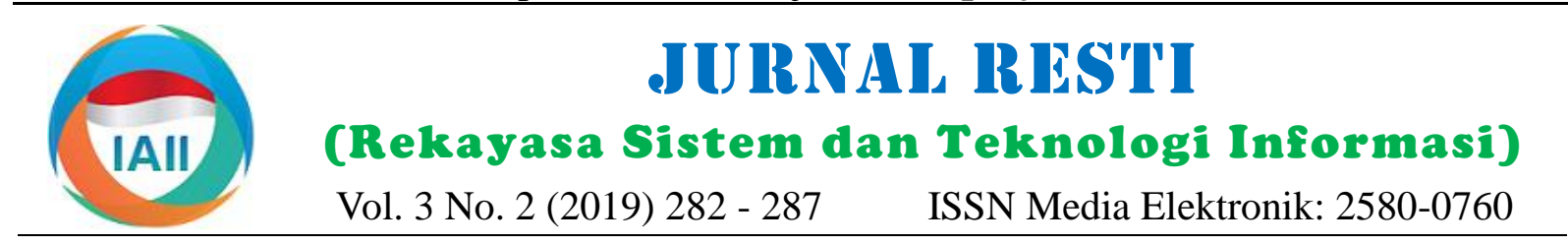

\title{
Analisis Pola Prediksi Data Time Series menggunakan Support Vector Regression, Multilayer Perceptron, dan Regresi Linear Sederhana
}

\author{
Ika Oktavianti ${ }^{1}$, Ermatita ${ }^{2}$, Dian Palupi Rini ${ }^{2}$ \\ Magister Teknik Informatika, Ilmu Komputer, Universitas Sriwijaya \\ 1'ioktavianti@vittal.org, ${ }^{2}$ ermatitaz@yahoo.com, ${ }^{3}$ dprini@ unsri.ac.id
}

\begin{abstract}
Licensing services is one of the forms of public services that important in supporting increased investment in Indonesia and is currently carried out by the Investment and Licensing Services Department. The problems that occur in general are the length of time to process licenses and one of the contributing factors is the limited number of licensing officers. Licensing data is a time series data which have monthly observation. The Artificial Neural Network (ANN) and Support Vector Machine (SVR) is used as machine learning techniques to predict licensing pattern based on time series data. Of the data used dataset 1 and dataset 2, the sharing of training data and testing data is equal to $70 \%$ and $30 \%$ with consideration that training data must be more than testing data. The result of the study showed for Dataset 1, the ANN-Multilayer Perceptron have a better performance than Support Vector Regression (SVR) with MSE, MAE and RMSE values is 251.09, 11.45, and 15.84. Then for dataset 2, SVR-Linear has better performance than MLP with values of MSE, MAE and RMSE of 1839.93, 32.80, and 42.89. The dataset used to predict the number of permissions is dataset 2. The study also used the Simple Linear Regression (SLR) method to see the causal relationship between the number of licenses issued and licensing service officers. The result is that the relationship between the number of licenses issued and the number of service officers is less significant because there are other factors that affect the number of licenses.
\end{abstract}

Keywords: pattern prediction, time series data, multilayer perceptron, support vector regression, simple linear regression

\begin{abstract}
Abstrak
Layanan perizinan adalah salah satu bentuk layanan publik yang penting dalam mendukung peningkatan investasi di Indonesia dan saat ini dilakukan oleh Dinas Penanaman Modal dan Pelayanan Terpadu Satu Pintu. Masalah yang terjadi secara umum adalah lamanya waktu untuk memproses izin dan salah satu faktor penyebab adalah terbatasnya jumlah petugas perizinan. Data perizinan adalah data deret waktu yang diobservasi setiap bulan. Artificial Neural Network (ANN) dan Support Vector Regression (SVR) digunakan sebagai teknik pembelajaran mesin untuk memprediksi pola perizinan berdasarkan data deret waktu. Dari data time series yang digunakan Dataset 1 dan Dataset 2, pembagian data pelatihan dan data pengujian sama dengan $70 \%$ dan $30 \%$, dengan pertimbangan bahwa data training harus lebih banyak dibandingkan data testing. Hasil penelitian menunjukkan bahwa untuk Dataset 1, ANN-Multilayer Perceptron memiliki kinerja yang lebih baik daripada SVR dengan nilai MSE, MAE dan RMSE adalah 251.09, 11.45, dan 15.84. Kemudian untuk Dataset 2, SVRLinear memiliki kinerja lebih baik dibandingkan MLP dengan nilai MSE, MAE dan RMSE sebesar 1839.93, 32.80, dan 42.89. Dataset yang digunakan untuk prediksi jumlah perizinan adalah dataset 2. Penelitian juga menggunakan metode Simple Linear Regression (SLR) untuk melihat hubungan sebab akibat antara jumlah izin yang terbit dengan petugas pelayanan perizinan. Hasilnya hubungan jumlah izin yang terbit dengan jumlah petugas pelayanan kurang signifikan karena terdapat faktor lain yang mempengaruhi jumlah izin.
\end{abstract}

Kata kunci: pola prediksi, data time series, multilayer perceptron, support vector regression, regresi linear sederhana 


\section{Pendahuluan}

Layanan perizinan adalah salah satu bentuk layanan publik yang penting dalam meningkatkan investasi dan pembangunan di suatu daerah. Reformasi birokrasi perizinan telah diimplementasikan sejak lama sebagai kinerja un bentuk upaya pemerintahan dalam memberikan batasan kesalahan umum dan untuk menghindari pelayanan prima kepada masyarakat. Hal ini masalah kelebihan beban. Kesalahan umum adalah dikarenakan berbagai masalah dalam perizinan, seperti perbedaan antara risiko empiris pada data pelatihan dan waktu pemrosesan yang lambat, persyaratan yang risiko hasil hipotesis. Dengan kata lain, mengukur tumpang tindih, pungutan liar terhadap investor dan seberapa akurat model untuk memprediksi nilai hasil lain-lain.

Peraturan Presiden Nomor 97 Tahun 2014 tentang Pelayanan Terpadu Satu Pintu di Bidang Penanaman Modal dikeluarkan untuk memberikan layanan yang lebih baik kepada warga negara serta mempersingkat proses layanan agar lebih cepat, mudah, murah, transparan, pasti dan terjangkau yang diimplementasikan dalam Pelayanan Terpadu Satu Pintu yang selanjutnya disingkat menjadi PTSP. PTSP adalah layanan terintegrasi mulai dari tahap permohonan hingga penyelesaian produk perizinan. Menindaklanjuti Peraturan Presiden di atas, ditetapkan bahwa PTSP berada dibawah ruang lingkup Dinas Penanaman Modal dan Pelayanan Terpadu Satu Pintu dan seluruh provinsi di Indonesia memiliki nomenklatur yang sama, yaitu DPMPTSP. DPMPTSP Provinsi Sumatera Selatan saat ini melayani 140 jenis perizinan dan non perizinan.

Berdasarkan masalah perizinan yang telah dijelaskan, penelitian dilakukan untuk mengindentifikasi pola prediksi data time series perizinan. Studi ini mengindentifikasi data perizinan yang diterbitkan secara berkala setiap bulan. Identifikasi berguna untuk menemukan pengetahuan dalam data. Berbagai pendekatan untuk prediksi digunakan dalam penelitian ini yaitu teknik machine learning. Support Vector Regression (SVR) and Neural Network adalah salah satu metode yang efektif dan menghasilkan algoritma terbaik dengan data yang terbatas [1].

Beberapa penelitian telah membuktikan bahwa metode SVR dan ANN mampu melakukan peramalan. Salah satunya adalah penelitian tentang prognosis kerusakan bantalan gelinding dengan menggunakan metode Support Vector Regression (SVR). Penelitian ini Penelitian ini menggunakan dataset perizinan yang dilakukan dengan menggunakan objek bantalan telah diterbitkan setiap bulan dari Agustus 2009 hingga gelinding karena bantalan gelinding merupakan Januari 2019. Data dibagi menjadi training set dan komponen yang mampu membuat sebuah mesin terus testing set secara default. $70 \%$ dari data digunakan berputar atau bekerja. Dengan melakukan prognosis sebagai training set dan $30 \%$ dari data digunakan terhadap kerusakan bantalan gelinding dapat sebagai testing set. Training data akan digunakan mengoptimalkan biaya perawatan mesin karena bisa sebagai input untuk Multilayer Perceptron (MLP) dan mengetahui sisa umur fungsi bantalan gelinding Support Vector Regression (SVR), sedangkan testing sebelum bantalan gelinding tersebut rusak [2].

Penelitian lainnya adalah penelitian mereka bahwa model Support Vector Regression dapat memprediksi dari data sebelumnya [4]. Metode Simple Linear Regression (SLR) juga digunakan dalam penelitian ini untuk membuktikan apakah ada hubungan yang signifikan antara jumlah izin yang terbit dengan jumlah petugas pelayanan. Diharapkan hasil penelitian ini akan membantu Pemerintah Provinsi Sumatera Selatan dalam merencanakan pengambilan keputusan dan kebijakan terkait peningkatan pelayanan dan Indeks Kepuasan Masyarakat (IKM).

\section{Metode Penelitian}

etode penelitian merupakan suatu proses tata cara an yang dilakukan untuk kepentingan penelitian. menggunakan data time series dan dengan menggunakan Support Vector Regression (SVR) dan Artificial Neural Network (ANN) - Multilayer Perceptron pada Dinas Penanaman Modal dan Pelayanan Terpadu Satu Pintu Provinsi Sumatera Selatan. Proses yang dilakukan pada penelitian dapat dilihat pada alur gambar 1 .

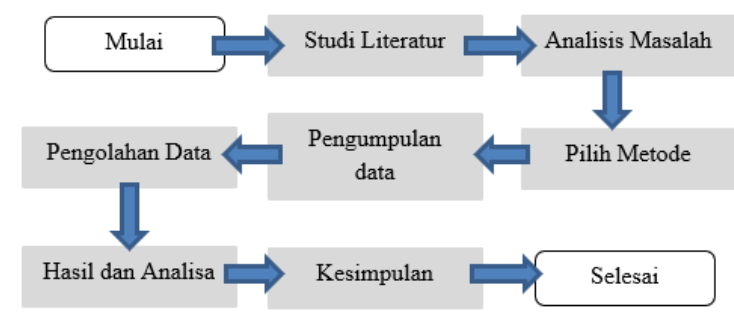

Gambar 1. Alur Proses Penelitian

data akan digunakan untuk prediksi. Kinerja MLPANN dan SVR diukur dengan Mean Square Error (MSE), Mean Absolute Error (MAE) dan Root Mean Square Error (RMSE). Gambar 2 menunjukkan hasil dalam penelitian yang berjudul Prediksi Pola Perizinan 
coding untuk menemukan hasil prediksi melalui Bahasa nilai hyperplane maka abstrak tersebut masuk dalam pemrograman phyton. Setelah model optimal, maka kelas negatif. Flowchart SVR Testing dapat dilihat didapat hasil MAE, MSE, RMSE untuk menentukan pada gambar 3.

apakah tingkat kesalahan yang terjadi dengan dataset tinggi atau rendah.Kemudian akurasi MLP-ANN dan SVR akan dibandingkan untuk melihat model yang lebih cocok untuk data time series dari dataset perizinan. Pada proses pelatihan SVR bertujuan untuk menemukan vektor $\alpha$, nilai $\mathrm{w}$ dan konstanta $\mathrm{b}$ untuk mendapatkan hyperplane terbaik. Dalam proses pelatihan dibutuhkan satu set data training dan data testing.

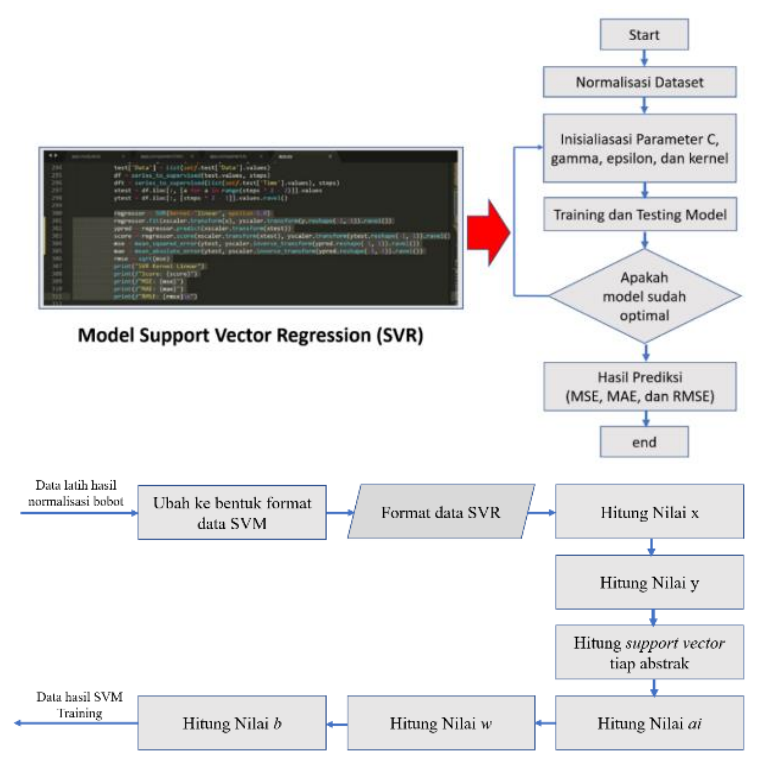

Gambar 2. Model Support Vector Regression

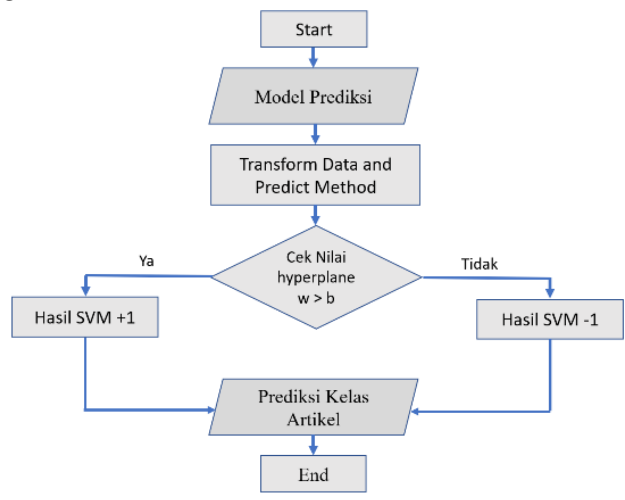

Gambar 3. Flowchart Support Vector Regression

\subsection{Pemodelan MLP}

ANN adalah model komputasi atau matematika yang terinspirasi oleh proses otak manusia [6]. Sistem dirancang untuk memecahkan masalah yang lebih kompleks. Neural Network terdiri dari beberapa neuron, neuron ini akan mengubah informasi yang diterima melalui outletnya ke neuron lain. Dalam Neural Network, hubungan ini dikenal sebagai bobot. Informasi ini disimpan pada nilai tertentu pada berat itu. Bobot masing-masing koneksi bersifat dinamis sehingga input yang diberikan menghasilkan output yang diinginkan. Model Artificial Neuron terdiri dari fungsi aktivasi. Fungsi aktivasi yang paling sering digunakan adalah fungsi hyperbolic tangent dan sigmoidal functions. Feed forward neural networks adalah yang terkenal di berbagai aplikasi di antara berbagai jenis koneksi untuk neuron buatan. Ia juga dikenal sebagai Multilayer Perceptron (MLP).

Data hasil pembobotan dan normalisasi diubah ke dalam format data SVR. Masukan yang pertama pada kelas adalah +1 atau -1 menyatakan dua label awalan yang diberikan. Tahap selanjutnya menghitung nilai $\mathrm{x}$. nilai $X$ pada tabel akan digunakan untuk perhitungan kernel. Selanjutnya yaitu melakukan kernelisasi menggunakan fungsi Kernel linier. Kemudian tahap selanjutnya adalah melakukan perhitungan terhadap y. Untuk nilai $y$ adalah nilai dari label yang diberikan. Tahap selanjutnya mengubah setiap abstrak menjadi nilai vektor (support vector) $=\begin{aligned} & x \\ & y\end{aligned}$ agar mendapatkan nilai ai. Setelah didapatkan nilai ai, maka akan didapatkan nilai w dan b. Model Support Vector Regression dapat dilihat pada gambar 6. Dalam Support Vector Regression, input x pertama-tama dipetakan ke Tahapan pemodelan Multilayer Perceptron Neural dalam ruang fitur menggunakan model linear untuk Network dimulai dengan penentuan jumlah hidden membangun input dalam ruang dimensi tinggi [5].

Setelah mendapatkan nilai $\mathrm{w}$ dan $\mathrm{b}$ atau hyperplane 2.3. Pemodelan SLR dari hasil SVM Training, selanjutnya dapat menentukan data abstrak masuk dalam kelas positif atau negatif dengan nilai $\mathrm{w}$ dan hyperplane tersebut. Jika nilai hasil uji lebih besar dari nilai hyperplane maka abstrak tersebut masuk dalam kelas positif, jika lebih kecil dari

Multilayer Perceptron (MLP) adalah feed forward neural network yang terdiri dari beberapa neuron yang terhubung dengan menghubungkan bobot. Setiap bobot terhubung ke setiap bobot pada lapisan berikutnya. Setiap MLP terdiri dari minimal tiga lapis dari input layer. Neuron-neuron ini tersusun dalam lapisanlapisan yang terdiri dari satu input layer, satu atau lebih hidden layer, dan satu output layer. Input layer menerima sinyal dari luar, kemudian meneruskannya ke hidden layer pertama, yang akan berlanjut hingga mencapai output layer.

layer. Tahapan pemodelan dapat dilihat pada gambar 4 .

Model persamaan Regresi Linear Sederhana dijelaskan dalam rumus 1.

$y=a+b x$ 

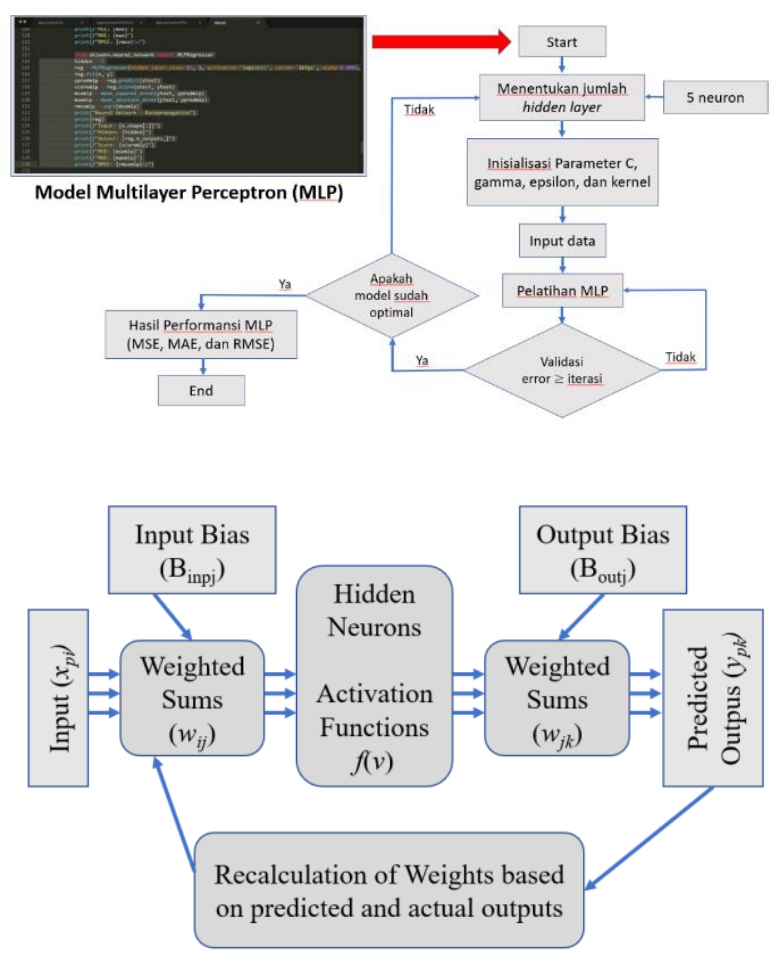

Gambar 4. Model Multilayer Perceptron

Untuk mendapatkan hasil persamaan regresi tersebut, hal pertama yang dilakukan adalah menentukan dataset sampel yang akan digunakan dan peneliti akan menggunakan jumlah izin dataset 2 yaitu dari bulan Februari 2016 sampai dengan bulan Januari 2019 yaitu sebanyak 36 data.

$\boldsymbol{x}$ adalah Jumlah Izin dan $\boldsymbol{y}$ adalah Jumlah Pegawai Pelayanan Perizinan (SDM). Untuk mengetahui nilai persamaannya, maka dicari nilai a dan b. Setelah dilakukan perhitungan, didapat nilai a dan $\mathrm{b}$ sebagai berikut:

$y=13,951+0,010832 x$

\section{Hasil Analisis dan Pembahasan}

\subsection{Plot Data}

Dalam penelitian ini, plot data dilakukan untuk menentukan trend pengurusan perizinan yang menjadi kewenangan provinsi setiap bulannya. Banyaknya perizinan yang diselesaikan setiap bulannya diharapkan dapat menggambarkan dan membantu menghasilkan model, variasi trend musiman bagi perusahaan untuk mengurus perizinannya. Plot data juga digunakan untuk menentukan teknik yang tepat dalam melakukan peramalan. Plot data time series dari dataset perizinan yang terbit setiap bulan dapat dilihat pada gambar 5 .

Gambar 5 diatas menunjukkan bahwa plot data time series yang digunakan dalam penelitian ini adalah plot data time series dengan 2 (dua) dataset berulang atau musiman setiap bulan. Pola ini membentuk siklus yang dapat membantu melakukan peramalan (forecasting).

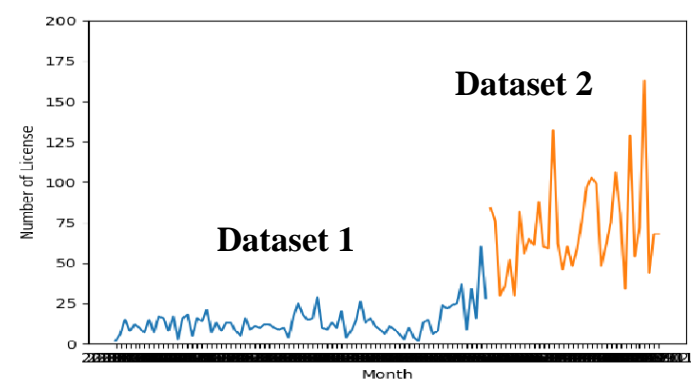

Gambar 5. Plot Data Time Series

\subsection{Hasil Analisis SVR dan MLP}

Dataset 1 terdiri dari 78 actual data jenis izin, data yang dilatih adalah $70 \%$ yaitu sebanyak 55 data dan data yang diuji untuk menghitung MAE, MSE, dan RMSE hanya $\pm 30 \%$ yaitu sebanyak 23 data. Hasil analisis dataset 1 adalah tingkat akurasi MLP lebih baik dibandingkan SVR-Linear yaitu score -0.17 dan nilai MSE, MAE dan RMSE sebesar 251.09, 11.45, dan 15.84. Terbukti nilai error MLP lebih rendah dibandingkan dengan SVR-Linear yaitu sebesar 15.84\%. Namun apabila dibandingkan dengan SVR fungsi kernel lainnya, maka SVR-Ridge lebih akurat dibandingkan dengan MLP dengan score -0.011 dan nilai MSE, MAE dan RMSE sebesar 215.33, 10.76, 14.67. Nilai error SVR-Ridge lebih kecil dibandingkan MLP yaitu $14.67 \%$. Grafik hasil perhitungan SVR dan MLP untuk dataset 1 dapat dilihat pada gambar 6 .

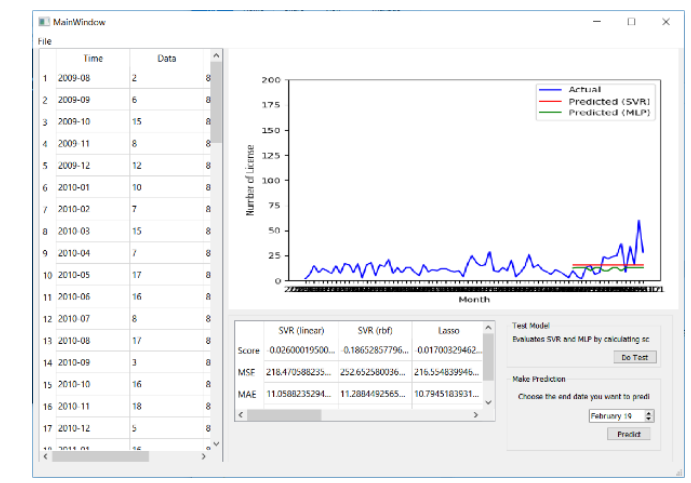

Gambar 6. Hasil SVR dan MLP Dataset 1 menggunakan Bahasa Program Phyton

Dataset 2 terdiri dari 36 actual data jenis izin yang ada, data yang dilatih adalah $70 \%$ yaitu sebanyak 25 data dan data yang diuji untuk menghitung MAE, MSE, dan RMSE hanya $\pm 30 \%$ yaitu sebanyak 11 data. Hasil analisis dataset 2 adalah tingkat akurasi SVR-Linear lebih baik dibandingkan MLP yaitu score -0.014 dan nilai MSE, MAE dan RMSE sebesar 1839.93, 32.80, dan 42.89 dan nilai SVR fungsi kernel lainnya. Terbukti nilai error SVR-linear lebih rendah 
dibandingkan dengan MLP SVR fungsi kernel lainnya oleh 4 orang agar pelayanan bisa optimal dan prima. yaitu sebesar $42.89 \%$. Hasil prediksi dan hasil tes data Hal ini diperlukan agar kinerja proses pelayanan dapat dilihat pada gambar 7 .

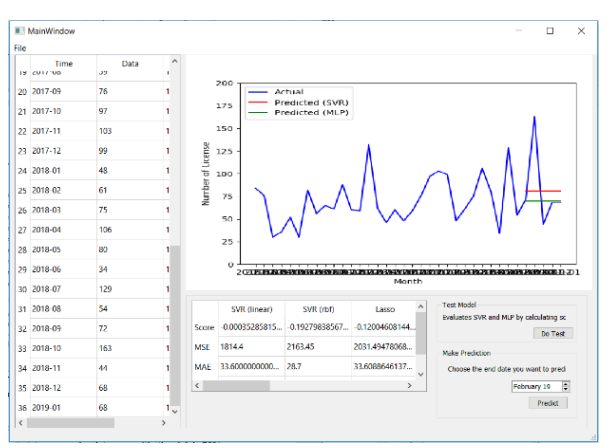

Gambar 7. Hasil SVR dan MLP Dataset 2 menggunakan Bahasa Program Phyton

Hasil prediksi (Predicted) izin yang akan terbit selama 3 bulan berikutnya apabila dibandingkan dengan hasil yang sebenarnya (actual) dapat dilihat pada grafik gambar 8 .

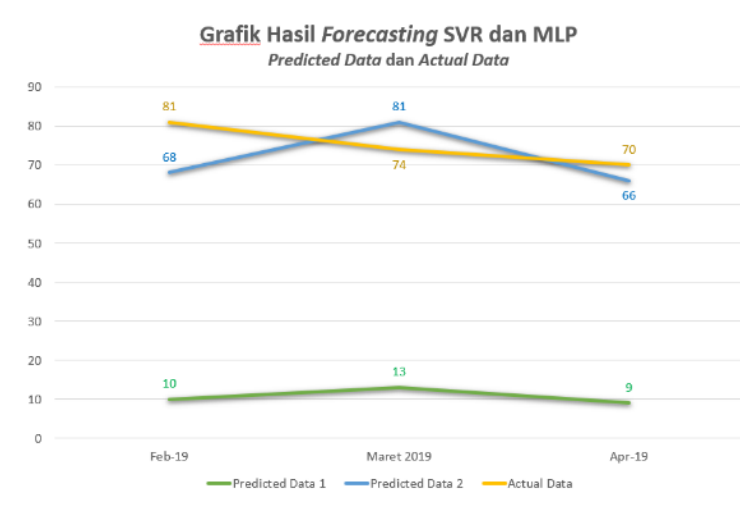

Gambar 8. Grafik Forecasting SVR dan MLP

Perhitungan yang dilakukan dengan menggunakan kedua dataset time series menghasilkan prediksi jumlah perizinan yang akan terbit di bulan dan tahun mendatang sangat berbeda. Hal ini disebabkan oleh adanya perubahan musim yang mengakibatkan hasil prediksi menggunakan dataset 1 tidak sesuai lagi dengan perkembangan perizinan sekarang. Sehingga walaupun nilai error berdasarkan dataset 1 lebih kecil dibandingkan dataset 2, tetapi yang bisa dijadikan acuan dalam memprediksi perizinan tetap berdasarkan hasil perhitungan dataset 2. Terbukti pada saat dibandingkan dengan hasil sebenarnya, prediksi menggunakan dataset 2 tidak terlalu jauh dengan hasil yang sebenarnya.

\subsection{Hasil Forecasting menggunakan SLR}

Setelah data dimasukkan ke dalam persamaan (10) metode Support Vector Regression (SVR) dan dengan menggunakan data random dari seluruh data Multilayer Perceptron (MLP) untuk memprediksi pola testing sebanyak 36 data, maka hasil peramalan yang perizinan. Hasil penelitian menunjukkan bahwa:

didapat bahwa berdasarkan jumlah izin yang terbit ratarata sebanyak 71 izin diperlukan petugas pelayanan (SDM) sebanyak 15 orang atau 1 izin harus dikerjakan perizinan dapat berjalan maksimal. Tabel 1 menunjukkan hasil perhitungan dan analisa apakah ada hubungan yang signifikan antara jumlah izin yang terbit dan jumlah petugas pelayanan perizinan.

Tabel 1. Hasil Regresi menggunakan SPSS

\begin{tabular}{|c|c|c|c|c|}
\hline Model & $\mathrm{R}$ & $\begin{array}{c}\mathrm{R} \\
\text { Square }\end{array}$ & $\begin{array}{c}\text { Adjusted R } \\
\text { Square }\end{array}$ & $\begin{array}{c}\text { Std. Error of the } \\
\text { Estimate }\end{array}$ \\
\hline 1 &, $258^{\mathrm{a}}$ &, 066 & 0.39 & 1,209 \\
\hline
\end{tabular}
a. Predictors: (Constant), izin

ANOVA $^{\mathrm{a}}$

\begin{tabular}{|c|c|c|c|c|c|}
\hline Model & $\begin{array}{c}\text { Sum of } \\
\text { Squares }\end{array}$ & df & $\begin{array}{c}\text { Mean } \\
\text { Square }\end{array}$ & F & Sig. \\
\hline 1 Regression & 3,531 & 1 & 3,531 & 2,416 &, $129^{\mathrm{a}}$ \\
Residual & 46,692 & 34 & 1,462 & & \\
Total & 53,222 & 35 & & & \\
\hline
\end{tabular}

a. Dependent Variable: Petugas

b. Predictors: (Constant), Izin

\begin{tabular}{|c|c|c|c|c|c|}
\hline \multirow{2}{*}{ Model } & \multicolumn{2}{|c|}{$\begin{array}{c}\text { Unstandardized } \\
\text { Coefficients }\end{array}$} & \multirow{2}{*}{$\begin{array}{c}\begin{array}{c}\text { Standardized } \\
\text { Coefficients }\end{array} \\
\text { Beta }\end{array}$} & \multirow{2}{*}{$\mathrm{t}$} & \multirow{2}{*}{ Sig. } \\
\hline & B & $\begin{array}{l}\text { Std. } \\
\text { Error }\end{array}$ & & & \\
\hline 1 (Constant) & 13,951 &, 536 & & 26,052 & ,000 \\
\hline Izin &, 011 & ,007 & ,258 & 1,554 &, 129 \\
\hline
\end{tabular}

Hasil analisis berdasarkan perhitungan Tabel 1 menggunakan program aplikasi Statistical Product and Service Solutions (SPSS), antara lain:

1. Persamaan yang dihasilkan dari perhitungan secara manual regresi linear sederhana sudah benar dan sesuai, yaitu a sebesar 13,951 dan b sebesar 0,011.

2. Nilai $\mathrm{R}$ Square 0,066 menunjukkan bahwa hubungan antara jumlah izin yang terbit dengan jumlah petugas yang melayani perizinan kurang signifikan karena hanya sebesar $6,6 \%$. Ada faktor lain yang lebih mempengaruhi jumlah izin yang terbit $(x)$, tidak hanya faktor jumlah petugas pelayanan $(y)$.

3. Hasil standard error of estimate yaitu sebesar 1,209 menunjukkan bahwa tingkat error untuk melakukan peramalan adalah sebesar 12,09\% yang berarti cukup tinggi. Hal ini dikarenakan standar error dalam suatu peramalan menggunakan simple linear regression adalah sebesar $5 \%$.

\section{Kesimpulan}

Penelitian ini menggunakan data time series dengan perizinan. Hasil penelitian menunjukkan bahwa:
1. Prediksi menggunakan data time series yang cukup banyak membuktikan bahwa metode MLP lebih

Jurnal RESTI (Rekayasa Sistem dan Teknologi Informasi) Vol 3 No. 2 (2019) 282 - 287 
akurat dibandingkan dengan metode SVR, dimana 2. Pemilihan parameter yang paling tepat dari fungsi nilai akurasinya adalah sebesar -0.17 dan nilai Mean Absolute Error (MAE) dan Root Mean Square Error (RMSE) adalah 11,45 dan 15,84 .

2. Prediksi menggunakan data time series yang sedikit membuktikan bahwa metode SVR lebih akurat dibandingkan dengan metode MLP, dimana nilai akurasinya adalah sebesar -0.014 dan nilai Mean Absolute Error (MAE) dan Root Mean Square Error (RMSE) adalah 32,80 dan 42,89.

3. Metode SVR dan MLP-ANN terbukti cukup baik digunakan untuk meramalkan suatu hal dan dengan dukungan data time series yang cukup banyak metode ini dapat menghasilkan pola prediksi yang lebih akurat.

4. Hasil peramalan menggunakan Simple Linear Regression (SLR), menunjukkan bahwa jumlah petugas pelayanan masih kurang dan pemerintah perlu menambah petugas pelayanan agar kualitas pelayanan perizinan dan Indeks Kepuasan Masyarakat (IKM) meningkat.

Saran yang direkomendasikan untuk pengembangan penelitian, antara lain:

1. Menggunakan pendekatan hybrid, yang merupakan kombinasi Artificial Neural Network (ANN) dan Support Vector Regression (SVR). kernel dan model Artificial Neural Network (ANN) serta diusulkan untuk menggunakan algoritma metaheuristic, Deep Learning, dan teknik algoritma dalam akurasi peramalan.

3. Mencari faktor lain yang dimungkinkan mempengaruhi variabel jumlah izin yang terbit selain dari petugas pelayanan (SDM).

\section{Daftar Rujukan}

[1] P. Meesad and R. I. Rasel., 2013. Predicting Stock Market Price Using Support Regression. International Conference on Informatics, Electronics and Vision (ICIEV).

[2] Ullu, H. H., 2013. Prognosis of Damage to Rolling Bearings Using the Support Vector Regression (SVR) Method. Universitas Diponegoro.

[3] Hasan, N., Rasel, R. I., and Nath, N. C., 2015. A Support Vector Regression Model for Forecasting Rainfall. International Conference on Electrical Information and Communication Technologies (EICT)

[4] A. Xu and M. Raginsky., 2017. Information-Theoretic Analysis of Generalization Capability of Learning Algorithm. $31^{\text {st }}$ Conference on Neural Information Processing System (NIPS). CA, USA.

[5] P. Kumar and P. Sharma., 2014. Artificial Neural Network-A Study. International Journal of Emerging Engineering Research and Technology, 2 (2), pp. 143-148.

[6] Nazzal, J. M., El-Emary, I. M., and Najim, S. A., 2008. Multilayer Perceptron Neural Network (MPNN) for Analyzing The Properties of Jordan Oil Shale. World Applied Sciences Journal, 5, 546-552. 